\title{
Prescription Opioids, Time to Rethink How We Assess Risk
}

\author{
Cynthia Kay, MD, MSc ${ }^{1,2}$ \\ ${ }^{1}$ Medical College of Wisconsin, Milwaukee, WI, USA; ${ }^{2}$ Clement J. Zablocki VA Medical Center, Milwaukee, WI, USA.
}

$\mathrm{J}$ Gen Intern Med 35(3):633-4

DOI: $10.1007 / \mathrm{s} 11606-019-05604-4$

(c) Society of General Internal Medicine (This is a U.S. government work and not under copyright protection in the U.S.; foreign copyright protection may apply) 2019

$\mathrm{W}$ hile the opioid epidemic was officially declared a public health emergency in 2017 , the USA has grappled with this problem for much longer. After 2017, the response to the crisis came at every level, from individual practices and healthcare establishments to state and national organizations and the government. The result was an influx of policies and laws aimed at reversing the epidemic, primarily by restricting the initial prescription of opioids. The CDC report from 2019 noted a decrease in the prescribing rates of opioids; however, opioid-related deaths have not followed suit. ${ }^{1}$ This discrepancy is without a clear explanation but raises numerous issues.

Traditionally, studies that examine opioid overdose deaths have labeled natural, semisynthetic, other synthetic opioids and methadone as "prescription" opioid. ${ }^{2,3}$ These same studies relied on the National Vital Statistics System multiple cause-of-death mortality files, and subsequently, the International Classification of Diseases, Tenth Revision (ICD-10) codes to identify "prescription" overdose. These codes convey the cause of death but do not confirm whether the medications were, in fact, prescribed to the deceased individual or obtained by other methods. While studies have found associations between "prescription" opioids and various negative outcomes, confirmed prescribed opioids and short-term mortality, in a national cohort, remain understudied.

In this issue of JGIM, Agnoli and colleagues present observational analyses of prescription opioids and short-term allcause mortality, utilizing the U.S. Medical Expenditure Panel Survey (MEPS). ${ }^{4}$ Patients receiving opioids had a higher mortality; compared with those receiving no opioids, those receiving $1-5$ prescriptions had 1.5 increase odds of death and those getting 6 or more were 3.2 times more likely to die. However, once adjusted for health status, the odds ratios for mortality were no longer significant. Similar findings were seen when adjusted for healthcare utilization.

The final model, which adjusted for all covariates, yielded odds ratios for both the $1-5$ and 6 or more opioid categories

Published online January 2, 2020 that were not significant when compared with the no opioid group. Higher age, male sex, and cancer were the most significant predictors of mortality.

The MEPS has a wealth of information. In addition to sociodemographic information, numerous scales are used, including the 12-item Short-Form Health Survey (SF-12) and Mental Component Summary (MCS). Participants' selfrating of their health is also incorporated, which is an important predictor of mortality. ${ }^{5}$ In general, large database research has not examined or incorporated patient-reported information. This makes the resultant patient-reported information a strength of MEPS data and this study particularly unique. However, the strength of the MEPS is also a limitation. There is a tendency for response bias with surveys, leading to uncertainty whether participants' responses would be different from non-participants, particularly regarding a sensitive topic as opioid use.

Agnoli et al. found that the ORs adjusted for sociodemographic covariates were consistent with those from studies that examined opioid dose, prescribing rates, and chronic use. ${ }^{6-8}$ However, dose was not included in this study. The adjustment for health status is the main difference between this and prior studies. Once adjusted for health status, the mortality association with opioid prescribing became insignificant. The implication of this is that sociodemographics alone are not enough to adjust for mortality with opioid exposure. Most of the measures included were "subjective" patient self-assessed health, which highlights the accuracy of patients' awareness of their own health. This might suggest that participants prescribed opioids view themselves as having worse health or that those with poor health have greater indications for opioids.

The lack of differences in short-term all-cause mortality between the three opioid categories is the most important finding from this study. Laws, policies, and regulations have generally targeted the initial prescribing of opioids as well as the continuation of opioids. ${ }^{9}$ These results question the assumption that any opioid exposure results in elevated risk for adverse events. This is one possible explanation for why opioid death rates have not mirrored opioid prescribing rates. Instead, participants' self-reported health status appears to be both a crucial factor and commonly omitted variable, in predicting mortality. 
These findings should place the interventions enacted to combat the opioid epidemic into a critical light. The significant effort and resources directed at prescription opioids is not without consequences. Some are positive, such as the decreased opioid prescribing rate. Others are more debatable. In particular, insurance companies and pharmacies have taken steps to limit opioid prescriptions, while some clinics and physicians have chosen to stop prescribing opioids altogether. ${ }^{10}$ When used judiciously, opioids are legitimate tools for combatting pain. Ultimately, the patients whom guidelines, policies, and laws were intended to protect could be unintended victims in this ongoing crisis.

Unfortunately, chronic pain remains prevalent. How healthcare providers manage and treat pain reflects programs and policies created from past research. Agnoli's results suggest that the current approach to combating the opioid epidemic may be misguided and in need of reassessment. The time may be now to redirect efforts to non-prescription opioids or patients' self-screening of health status, rather than primarily attempting to dissuade or impede opioid prescribing. Additional studies designed to explore causality and directly comparing opioid dose and exposure frequency to no opioids are needed to further clarify opioid risk.

Over the last few decades, the pendulum for prescribing opioids has swung from one extreme to the other. Initially, providers prescribed opioids for acute pain related to injury, surgery, or terminal illness. Prescriptions rose slowly through the 1980s, then exploded in the 1990s when an aggressive pharmaceutical campaign led providers to believe that opioids were safe and rarely addictive. Now, providers bear much of the burden and blame for the US opioid addiction. Targeting providers is, after all, much easier than facing hard truths about poverty, disparities, and social inequity. Management of chronic pain is complex and requires multi-disciplinary approaches. Opioids are just one tool in a provider's armamentarium for helping patients. A highly individualized, patientcentered approach may be more beneficial than broad, allencompassing polices.
Corresponding Author: Cynthia Kay, MD, MSc; Medical College of Wisconsin, Milwaukee, WI, USA (e-mail: Cynthia.kay@va.gov).

\section{Compliance with Ethical Standards:}

Conflict of Interest: The author has no conflicts of interest. The opinions expressed in this article reflect those of the author and should not be construed in any way to be those of the US Government or the Department of Veterans Affairs.

Publisher's Note: Springer Nature remains neutral with regard to jurisdictional claims in published maps and institutional affiliations.

\section{REFERENCES}

1. Centers for Disease Control and Prevention. Opioid Overdose: Understanding the Epidemic. Available at: https://www.cdc.gov/ drugoverdose/epidemic/index.html. Accessed September 29, 2019.

2. Rudd RA. Increases in drug and opioid-involved overdose deaths-United States, 2010-2015. MMWR Morb Mortal Wkly Rep. 2016;65.

3. Jones CM, Mack KA, Paulozzi LJ. Pharmaceutical overdose deaths, united states, 2010. JAMA. 2013;309(7):657-9.

4. Agnoli A, Jerant A, Becker W, Franks P. Opioid Prescriptions and ShortTerm Mortality: A U.S. National Study. J Gen Intern Med. DOI: https:// doi.org/10.1007/s11606-019-05501-w

5. DeSalvo KB, Bloser N, Reynolds K, He J, Muntner P. Mortality prediction with a single general self-rated health question: A metaanalysis. J Gen Intern Med. 2006;21(3):267-75.

6. Dunn KM, Saunders KW, Rutter CM, et al. Opioid prescriptions for chronic pain and overdose: a cohort study. Ann of Intern Med. 2010;152(2):85-92.

7. Dilokthornsakul P, Moore G, Campbell JD, et al. Risk factors of prescription opioid overdose among Colorado Medicaid beneficiaries. J Pain. 2016;17(4):436-43.

8. Paulozzi LJ, Kilbourne EM, Shah NG, et al. A history of being prescribed controlled substances and risk of drug overdose death. Pain Med. 2012;13(1):87-95.

9. Arizona Department of Health Services: State-by-State Summary of Opioid Prescribing Regulations and Guidelines. Available at: https:// www.azdhs.gov/documents/prevention/womens-childrens-health/injury-prevention/opioid-prevention/appendix-b-state-by-state-summary. pdf. Accessed September 28, 2019.

10. NEJM Catalyst. The Physicians' Quandary with Opioids: Pain versus Addiction. Available at: https://catalyst.nejm.org/quandary-opioidschronic-pain-addiction/. Accessed September 29, 2019.

Publisher's Note Springer Nature remains neutral with regard to jurisdictional claims in published maps and institutional affiliations. 